\title{
Roadmap for User-Performance Drive Lighting Management Logic
}

\author{
R. M. López, M. T. Aguilar, S. Domínguez-Amarillo, and M. A. Campano
}

\begin{abstract}
Smart control systems, especially lighting ones, have become essential in energy-saving fields. However, these technologies can be implemented in buildings with other objectives such as ensuring human health.

Unsuitable light exposure can seriously endanger human health due to the circadian rhythm disruption. Considering all lighting parameters, a suitable Circadian Stimulus (CS) can be achieved. Thus, the regulation of this variables by control systems to promote a good circadian rhythm and to benefit human health and well-being is crucial.

The main aim of this research is to set up the keys to develop a novel control scheme that include CS levels as the main factor to consider. From the study of already developed methodologies this research concludes with a diagram proposal to be considered in the development of the new algorithm of lighting control systems.
\end{abstract}

Index Terms - Lighting control systems, circadian stimulus, optimization, control logic, algorithm.

\section{INTRODUCTION}

Building technologies and services represent more than one-third of the primary energy consumption at the global level [1] so the reduction of the environmental impact is crucial for global sustainability [2], even for assuring self-sustainability and affordable running costs. One of the most influential factors in the energy consumption is the lack of control of building energy performance [3] causing a gap between the adaptation of the building — and its systems - to actual use-conditions and performance needs. Thus, Building Automation and Control Systems (BACS) become essential. Buildings provided with BACS capabilities have the backbone to become "smart" buildings in their operation [4].

One of the critical fields for building responsive behaviour is lighting and shading control systems [3]. A significant part of the energy consumption in office buildings is spent on electric lighting, so its control and coordination with natural light greatly contributes to energy savings [5], [6], contributing to comfort by tuning lighting to the use of different spaces and external conditions. Moreover, the use of natural or electric light sources has a direct impact on HVAC operation and loads [7].

However, not only does light contribute to energy savings

Manuscript received December 30, 2018; revised March 1, 2019. This work was supported by the research and development project 'Efficient design for biodynamic lighting to promote the circadian rhythm in offices buildings' (ref BIA2017-86997-R), as well as the TEP-130 Research group.

R. M. López, M. T. Aguilar, S. Domínguez and M. A. Campano are with the Department of Building Construction I, Universidad de Sevilla, Spain (e-mail: remloplov@alum.us.es, maragucar3@alum.us.es, sdomin@us.es, mcampano@us.es). but it also affects productivity, work performance, alertness [8], [9] and also users health and well-being. Recent investigations have shown the influence of lighting in the circadian rhythms, endogenous cycles that repeat almost every 24 hours [10]-[12], and the harmful effects of the circadian rhythm disruption on human health [13]-[15]. Light requirements of the circadian system are not the same throughout the day. It have been proved in the latest investigations carried out by Figueiro et al. [15] that the exposure to CS (Circadian Stimulus) must be higher during the day than during the night. The lighting control and therefore the circadian stimulus control becomes essential especially in office buildings with shift workers who are exposed to CS levels much higher than suitable ones during the night. As a consequence of this, the effects of the circadian rhythm disruption in shift workers are worse [16], [17].

The Spectral Power Distribution (SPD) and the Correlated Colour Temperature (CCT) of the light emissions and the intensity of light radiation received by inhabitants and users are the variables that condition the influence of light on the synchronization of the circadian rhythms [18], [19]. According with that, all these parameters must be considered in lighting control systems. Nevertheless, LED smart lighting systems usually control only the illuminance at the work plane producing light with a fixed SPD and CCT while new intelligent lighting systems that optimize other light parameters are still limited. [20].

The development in LED lighting technologies: from mixed colour systems, RGB sources and tunable white systems; allow that new investigations about novel approach to task and performance-based control for indoor light with many different constrains are carried out. The main aim of this paper is to present the keys to develop a novel algorithm that goes beyond the conventional smart lighting systems and allows for providing a suitable CS level at every moment of the day according to recent researches [15].

\section{CONTROL SYSTEMS}

As introduced before, to develop a control algorithm for a lighting system, it will be necessary to figure out, first, the characteristics of the control system to determine its structure according to the input and output of data, the relationship between sensors and actuators and the controller or the control strategy. Furthermore, we must know what the control system components are and how they work, for which sensors, actuators and controllers will be defined, as well as the input information to the system. 


\section{A. Control Diagram}

Feedforward and feedback are two classics approaches to manage the problem. In the first type, the input variables are previously defined so that the controller responds to changes in these variables. In a feedback control scheme, an objective value is determined so that the measured input variable is compared to this value [2]. In this way and as it is demonstrated in several methodologies [2], [6], [21]-[23] where lighting systems are developed, it seems that the most appropriate is the feedback control, since it allows the levels of illumination of the controlled area to be measured constantly, so that the variables of the system are adjusted according to the parameters detected [6].

\section{B. System Architecture}

The components of the control system will be controlled by a central node with a hierarchical structure to individual unit. Three categories are set up referring to the system architecture. The first case corresponds to a centralized architecture; all the sensors send the information to a central controller and this transmits the input parameters to the fixtures [22]-[25]. In a decentralized light control system each luminaire work individually, so that they have its own sensor and controller [22], [23], [26], [27]. In a distributed lighting control system there is no central controller; the fixtures communicate with each other directly [22], [26]. Thus, the last lighting control system architecture will be discard due to the control schema that the lighting control system proposed will need a controller. A scheme of each architecture is developed in Fig.1.

\section{Control Strategy}

Nowadays control logic has raise to two basic styles: rule based control (RBC) or model based control (MBC) [2]. In $\mathrm{RBC}$ the system is controlled directly, using sensors and actuators. Individual components area executed following a direct logic and they usually work according to pre-established rules according the schema: "if (antecedent), then (consequent)". MBC instead works following an indirect logic. Thus, MBC uses models that simulate the behaviour of the building, choose the best control strategy by comparing several options. The system does not follow a series of predetermined rules; it is able to adapt to any situation.

\section{Fixtures}

Developing a lighting control system needs to properly choose the fixtures that integrate it. Thus, several lighting control methodologies have been analysed to figure out which are the mainstream to be followed.

\section{E. Sensors}

Lighting sensor will be vital in this system, both to know the level of external light that enters trough the holes (placed next to these holes) [6], [21], [23], [28]-[30] and the levels of illumination perceived by the user (located at eye level, depending on the activity) [21], [23], [31], [32].

Presence or occupancy detectors are very important in the lighting control systems [6]. According to several researches, multiple sensing modules related to presence or occupancy of users can be misleading [6], [22], [33], thus many researchers claim that it is preferable to use several types of sensors to reduce the system error [34]. Traditionally PIR or ultrasonic passive motion sensors have been used, but these are not very precise because they lose efficiency as users move away [6], [22].

New lines of research related to technologies that include radio frequency identification that offer an improvement in occupancy detection are being proposed, for example RFID sensors based on personal tags for each user which are adaptable to identification cards [6], [33].

Recently developed methodologies are using the advantages offered by mobile devices to use both light sensor and presence sensor. In the use of these devices as a light sensor, its developers tested the light sensor on a Smartphone verifying that the measurements produced were of high precision [29]. This allows the continuous visual comfort of the user since the sensor of the device is measuring in real time each user's situation and adapting the luminaires to their preferences. In relation to the use of mobile devices as a presence detector, the development of a lighting control system based on user occupancy known as WinLight is proposed. It consists of a combination of motion sensors with signals emitted by the Smartphone. Users pre-set their

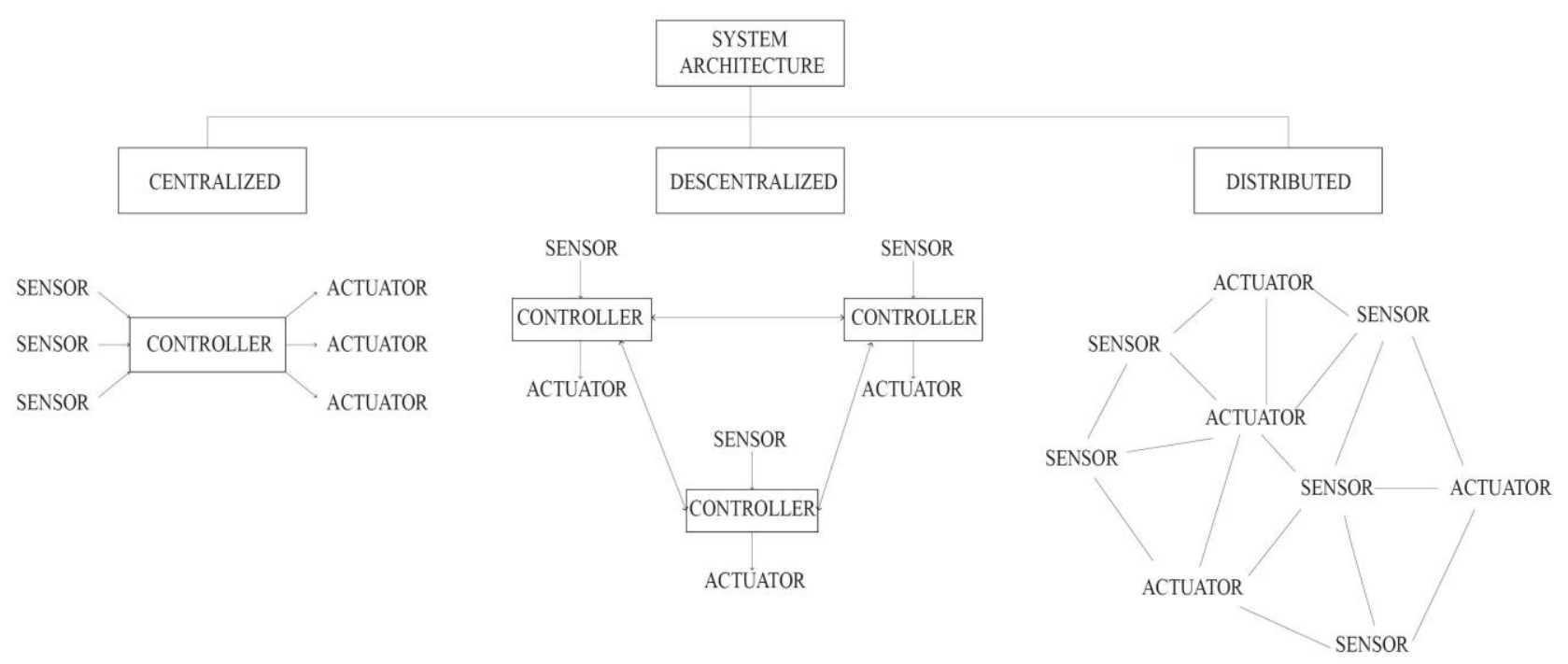

Fig. 1. Centralized, decentralized and distributed architecture scheme. 
preferences regarding levels of illuminance and other variables that the system process when the users devices are detected by the system [22].

Accordingly, a new fixture of the system appears: mobile device. Thus, as explained above, mobile device participle directly in the lighting controls system.

\section{F. Actuators}

Actuators are related to the output elements of the system. Thus, for a lighting control system it will be necessary to consider both the outputs of the luminaries and the sun protection elements. In addition, in the latest methodologies, ON/OFF actuators are being discarded in order to use brightness or intensity regulation of the luminaires [21], [23] or blinds regulation according to orientation, solar gains or preference of the users [21], [28].

\section{G. Controllers}

Controllers are essential in the development of these control systems. As previously introduced, depending on the architecture of the system, there may be a single controller for all device or a local controller for each one [22], [23]. The controller is defined by a series of control modes that are [1]: ON/OFF, P (proportional), PI (proportional/integral), PID (proportional/integral/derivative), AI (artificial intelligencelearning). Despite the fact that ON / OFF control modes have traditionally been used for lighting systems, it would be interesting to be able to develop an artificial intelligence control mode based on learning [2], [23], [31], [32] so that in addition to allowing a control adapted to each circumstance, it is improved energy efficiency. Although these control modes for this type of systems are still being studied, there are examples of lighting control systems that use PI [23], [29] or PID [21], [35] controllers.

\section{H. Inputs:}

It will be important to determine which parameters will condition the control scheme. Thus, these parameters can be differentiated into two categories: fixed input parameters and environmental input variables. The fixed input parameters are divided into two: those that are set according to specific users preferences [22], [31], [32], [36] and others that are more related to standards or rules such as the levels of illuminance depending on the developed activity [23], [37], [38]. The environmental input variables are related to the background illuminance [21], [32], [39] and the received illuminance in the work plane [40]-[42], taking into account the possible reflections that objects may cause [6], [42], [43].

Considering the former, several methodologies that focus on the control logic of these lighting systems are analysed. Thus, starting from a model proposed in 2004 within a control algorithm was presented. The algorithm integrated lighting systems and blinds controller both manually and automatically. This is based on two main inputs: occupancy and illuminance in the work plane. Other factors such as the entrance of natural light are considered in this algorithm. The developers propose the prediction of the use of electrical lighting according to patterns of probabilistic behaviour [28].

Although the developed algorithm establishes adequate criteria for the development of lighting control systems, it presents several limitations. The most important is that both the blinds and the luminaires only work in ON/OFF mode and are not adjustable. In addition, climatic considerations are considered which also affect the position of the blinds and as consequence, the luminaires.

This will be the starting point of the lighting control systems. Thus, different proposals that contribute advances from this algorithm will be analysed.

\section{CONTROL LOGIC}

In relation to the earlier section, different algorithm methodologies to develop a lighting control system are analysed. Thus, one of the most significant advances has to do with the combination of the lighting system with HVAC system since the blind control influences thermal gains among other parameters [21]-[23][31]. Environmental variables have been introduced as input of the system, so that knowledge of daylight levels in real time has become an important variable in these systems [21], [23], [29]. Several researchers have notice that the user is one of the most important fixtures of a control system and as there is a probability that the occupants do not use the systems properly, they have been proposed in multiple methodologies to use adaptive control employing learning techniques by analysing the behaviour of the users [21]-[23], [29], [31], [32]. The most innovative algorithms include the use of smartphones that make both sensors and interface between the system and de user using app to control their preferences [22], [32]. It is important to note that most systems only include actuators that work ON/OFF. In some cases the modification of the intensity of the light is mentioned [23], [32].

We can understand that these advances can be classified into three categories: task-oriented, performance-oriented and user-oriented. Factors such as glare caused by objects or by natural light could be categorized as a task-oriented input [6], [23], [40]. Related to performance-oriented we can highlight energy saving as the key to many methodologies [33], [39], [44] In terms of users-oriented, many authors base their algorithms on the specific needs of users, with comfort being the most relevant [2], [23], [32]. Table I shows the relationship of these concepts with each methodology.

A literature review has been carried out to identify the main trends, oriented to define those innovative approaches. Then a summary table of the recently developed algorithms is presented, starting from the first one mentioned above, and in which is proposal, methodology and inputs are included in Table II.

TABLE I: RELATIONSHIP PARAMETER-METHOLOGY

\begin{tabular}{|l|l|l|l|}
\hline Proposal & Task-oriented & $\begin{array}{l}\text { Performance- } \\
\text { oriented }\end{array}$ & User-oriented \\
\hline Soori et al. [21] & & $\mathrm{x}$ & \\
\hline Gunay et al.[31] & & $\mathrm{x}$ & $\mathrm{x}$ \\
\hline $\begin{array}{l}\text { Pandharipande et } \\
\text { al. [23] }\end{array}$ & & $\mathrm{x}$ & $\mathrm{x}$ \\
\hline Gunay et al. [32] & $\mathrm{x}$ & & $\mathrm{x}$ \\
\hline Tang et al. [29] & & $\mathrm{x}$ & $\mathrm{x}$ \\
\hline Zou, et al. [22] & & & \\
\hline
\end{tabular}


If we classify these methodologies considering the categories mentioned before, we can highlight that although multiple proposal corresponds to the three, most of them fall into two of these categories. In this way, Table I is proposed where this analysis is shown.

All these aspects analysed allow the definition of a scheme of relationships through which the selection of suitable elements to propose a control logic take place. Considering the conclusions obtained from the analysis of the methodologies, the workflow that will be developed in the future will be based on this [Fig. 2].

TABLE II: SUMMARY OF LIGHTING CONTROL AlgORITHM METHODOLOGIES

\begin{tabular}{|c|c|c|c|c|c|}
\hline Author & Key aspects & Proposal & Inputs & Methodology & Year \\
\hline Soori et al. [21] & $\begin{array}{l}\text { Mix of natural and } \\
\text { artificial lighting with } \\
\text { HVAC system to improve } \\
\text { energy system. }\end{array}$ & $\begin{array}{l}\text { A control lighting system } \\
\text { considering day lighting and a } \\
\text { system that combines lighting } \\
\text { control and HVAC control. } \\
\text { Furthermore, they seek the } \\
\text { energy efficiency and the users } \\
\text { comfort. }\end{array}$ & $\begin{array}{l}\text { - Daylight } \\
\text { - Lighting control + } \\
\text { HVAC } \\
\text { - Occupant } \\
\text { behaviour pattern }\end{array}$ & $\begin{array}{l}\text { Systems simulation software (FX) } \\
\text { is used to guarantee energy } \\
\text { efficiency. In this way, a control } \\
\text { algorithm is developed based on } \\
\text { PID controller composed by three } \\
\text { feedback loops to control the } \\
\text { position of the blinds, the } \\
\text { requirements of the luminaires } \\
\text { and the HVAC system. }\end{array}$ & 2012 \\
\hline Gunay et al.[31] & $\begin{array}{l}\text { Use of adaptive control } \\
\text { techniques to know the } \\
\text { users preferences through } \\
\text { the learned behaviours to } \\
\text { control luminaries and } \\
\text { blinds. }\end{array}$ & $\begin{array}{l}\text { An algorithm based on an } \\
\text { adaptive occupant learning } \\
\text { control system has been } \\
\text { developed to control both the } \\
\text { lighting system and the blinds. }\end{array}$ & $\begin{array}{l}\text { - Learning model } \\
\text { - Users control }\end{array}$ & $\begin{array}{l}\text { Using simulation techniques, a } \\
\text { Kalman filter has been used to } \\
\text { relate the fixed input algorithm } \\
\text { variables with the user behaviour. }\end{array}$ & 2014 \\
\hline $\begin{array}{l}\text { Pandharipande et al. } \\
{[23]}\end{array}$ & $\begin{array}{l}\text { Development of control } \\
\text { scheme according both the } \\
\text { occupation and the } \\
\text { daylight to achieve an } \\
\text { efficient lighting system }\end{array}$ & $\begin{array}{l}\text { An intelligent system is } \\
\text { proposed whose main input is } \\
\text { the sensors for both lighting } \\
\text { and occupancy. Thus, each } \\
\text { luminaire has integrated a } \\
\text { sensor of each type. }\end{array}$ & $\begin{array}{l}\text { - Adaptive control } \\
\text { - Daylight } \\
\text { - Occupant } \\
\text { behaviour pattern } \\
\text { - Learning model }\end{array}$ & $\begin{array}{l}\text { It starts from the reading of the } \\
\text { sensors so that the information } \\
\text { received is used as a pattern to } \\
\text { modify the luminaires and the } \\
\text { blinds. }\end{array}$ & 2015 \\
\hline Gunay et al. [32] & $\begin{array}{l}\text { Learning user behaviours } \\
\text { regarding the use of } \\
\text { lighting systems and } \\
\text { blinds, an adaptive control } \\
\text { algorithm is proposed for } \\
\text { these systems according to } \\
\text { the preferences of the } \\
\text { users. }\end{array}$ & $\begin{array}{l}\text { An algorithm is proposed for } \\
\text { the control of lighting and } \\
\text { blinds. It is an adaptive control } \\
\text { system based on learning } \\
\text { according to the preferences of } \\
\text { the users to determine the } \\
\text { parameters set in accordance } \\
\text { with the user's behaviour. }\end{array}$ & $\begin{array}{l}\text { - Regression model } \\
\text { Markov } \\
\text { - Adaptive control } \\
\text { - Learning model }\end{array}$ & $\begin{array}{l}\text { The algorithm is based on a } \\
\text { discrete time logic according to } \\
\text { the Markov logistic. Thus, the } \\
\text { lighting system is switched on an } \\
\text { off as well as the closing and } \\
\text { opening of blinds. }\end{array}$ & 2016 \\
\hline Tang et al. [29] & $\begin{array}{l}\text { Development of a control } \\
\text { algorithm using the } \\
\text { feedback scheme, in } \\
\text { which the smartphone is } \\
\text { included as an element of } \\
\text { the lighting control } \\
\text { system. }\end{array}$ & $\begin{array}{l}\text { A smart system of lighting is } \\
\text { developed, conditioned both } \\
\text { by the users occupancy and by } \\
\text { the daylight. Thus, a control } \\
\text { algorithm is proposed that } \\
\text { includes these input variables } \\
\text { to also improve energy } \\
\text { efficiency. }\end{array}$ & $\begin{array}{l}\text { - Occupant } \\
\text { behaviour pattern } \\
\text { - Daylight } \\
\text { - Smartphone } \\
\text { - App users control }\end{array}$ & $\begin{array}{l}\text { A system consisting of an } \\
\text { application for smartphone, } \\
\text { luminaires and PI controller is } \\
\text { developed. The PI controller also } \\
\text { acts as the main controller, } \\
\text { interface between the mobile } \\
\text { application and the luminaires. }\end{array}$ & 2016 \\
\hline Zou, et al. [22] & $\begin{array}{l}\text { Development of a lighting } \\
\text { control system that boosts } \\
\text { energy savings by } \\
\text { focusing on the comfort of } \\
\text { the occupants. }\end{array}$ & $\begin{array}{l}\text { A lighting control system } \\
\text { based on user occupancy } \\
\text { known as WinLight has been } \\
\text { proposed }\end{array}$ & $\begin{array}{l}\text { - Occupant } \\
\text { behaviour pattern } \\
\text { - Smartphone } \\
\text { - App users control }\end{array}$ & $\begin{array}{l}\text { Occupation is taken into account } \\
\text { by combining motion sensors with } \\
\text { signals emitted by users' smart } \\
\text { devices so that they pre-set a series } \\
\text { of preferences regarding the levels } \\
\text { of illuminance and other variables } \\
\text { that the system takes into account } \\
\text { when their devices are detected by } \\
\text { the system }\end{array}$ & 2018 \\
\hline
\end{tabular}




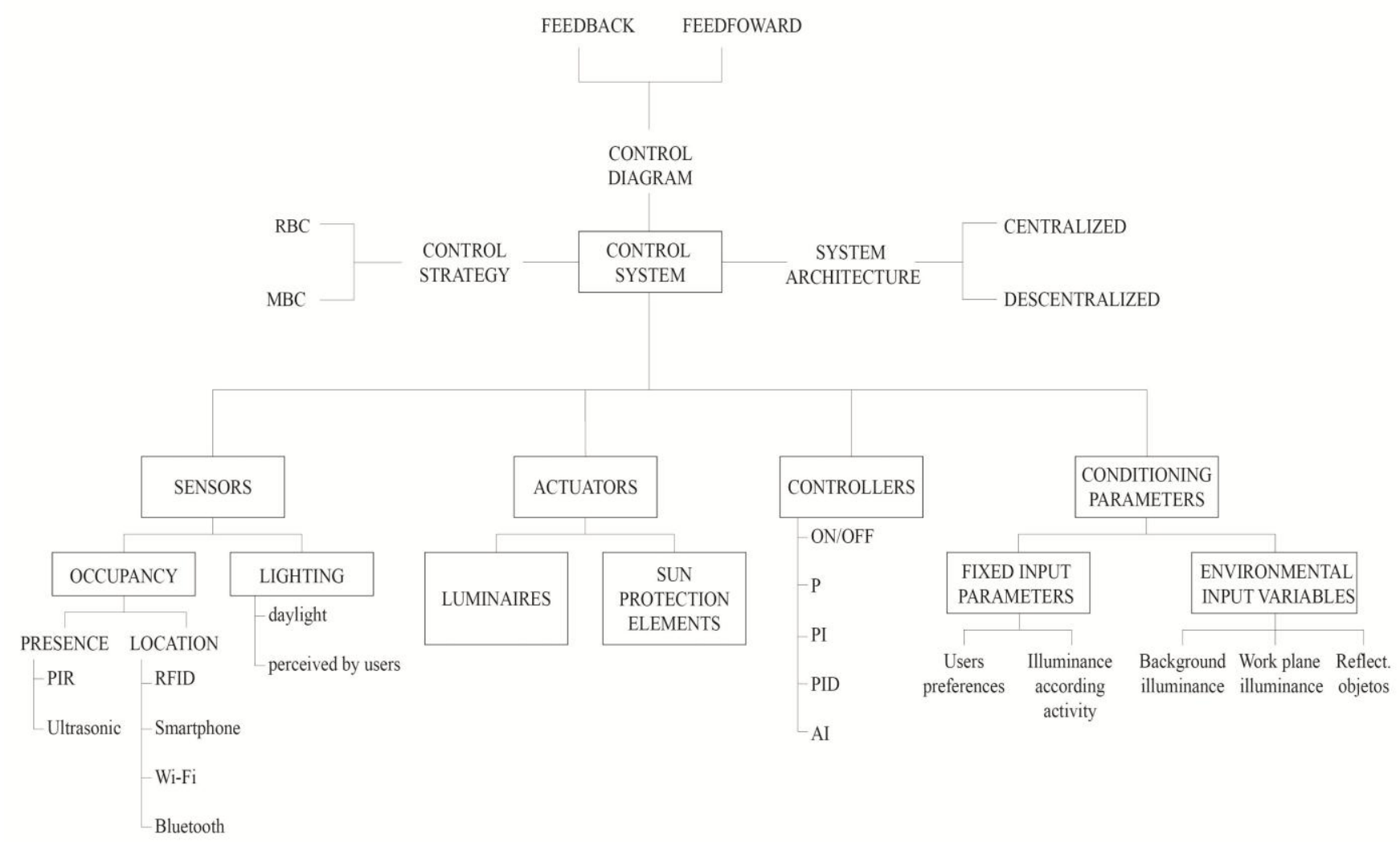

Fig. 2. Control system scheme.

\section{NOVEL LiGHTING CONTROL SYSTEMS AND THE CIRCADIAN RHYTHMS}

As we have said, smart light systems allow us to regulate the CS for the promotion of a suitable circadian rhythm through the control of the different variables that influence this metric: SPD, CCT and illuminance. Although studies about new algorithms for the control of all of these variables are limited, they must be studied.

Some of these studies are focused in the CCT, apart from the illuminance levels, using different control schemes. Studies carried out by Chen et al. and Lee et al. show control schemes implemented on a bi-color LED lighting system in which illuminance and CCT are control from a non-linear approach [45][46]. Other studies develop new control schemes implemented on RGB primary emitters. In these schemes illuminance and CCT are regulated by adjusting each channel individually [47]. The CCT can be also regulated on a multi-color LED light with which a more accurate CCT is achieved [48].

Other investigations are focused in the SPD regulation. An example of this is the control system carried out by Fryc et al. [49][50], the spectrally tunable source (STS). The control scheme is implemented in a multiple LEDs light source that can mimic different SPDs. However, the STS is normally used to calibration aims instead of general lighting.

Not only does the individual control of each of these parameters contribute to the promotion of a good circadian rhythm but also to the lighting system optimization. Moreover the irregular impact of daylight inside the buildings makes that topics such as the individual control of each lamp must be considered in order to get a good

\section{CONCLUSIONS}

In this paper we propose a review of the approaches to set up logic for lighting systems management, through the use of different control algorithms.

Of these approaches, fundamentally based on performance as a static goal, we can highlight those based on the user as the main element for the management of the system as the more potential path for future development. In those users-health is one of the key aspects driving the system. These can be configured as inhabitant's health-enhancing building components.

Basic control algorithms have grown in capacity and factors under consideration increasing complexity in their evolution. Although the most basic approaches are still useful in some applications, the need to provide an adaptive and user-friendly environment requires the incorporation of multi-parametric systems and the provision of complex logics, not necessarily linear (fuzzy-logic) to allow the, in most cases, complex optimization problems.

The technology evolution has been focused on occupant detections techniques, natural daylight integration and the progressive incorporation of adaptive control strategies by learning algorithms - based in the behaviours and preferences of the occupants.

In this context, a game changer player has appeared radically altering the earlier approaches: the emergence of smartphones as an interface between users and the surrounding environment show unprecedented capacities in the resolution of data exchange between the different actors in the game, allowing acting as a pivotal proxy.

The use of these devices facilitates not only the user-system two way traditional linear communications: since it is 
proposed that they are able to control and regulate the lighting, solar protection or HVAC systems through an app installed on these devices., but to act as a multi-capacity translator for readings and measurement of individual users reactions to local environment and personal evolution.

However, although many methodologies propose the development of algorithms with adjustable responses, it has not really been already proven effectively.

Moreover, new schemes about algorithms to regulate not only illuminance but also other parameters such as SPD and CCT have been shown and it will serve us like a starting point to develop a lighting control system that ensures suitable and healthy workspaces, providing a good regulation of the circadian rhythm. All these variables regulation becomes essential to provide suitable CS levels, especially during the night when light exposure compromises human health the most because good CS values cannot be achieved with conventional smart lighting systems. Machine learning techniques and Artificial Intelligence shows the way to follow in next step.

\section{ACKNOWLEDGMENT}

The results presented were funded by the government of Spain through the research project: Efficient design for biodynamic lighting to promote the circadian rhythm in shift work centres (Ref BIA2017-86997-R). The authors wish to express their gratitude for all the technical and financial support provided. Also, to the School of Architecture of the University of Seville as this work has been developed as architectural degree final project where have been awarded with the highest mark.

\section{REFERENCES}

[1] I. Nolte and D. Strong, Europe' S Buildings Under the Microscope.

[2] N. Aste, M. Manfren, and G. Marenzi, "Building automation and control systems and performance optimization: A framework for analysis," Renew. Sustain. Energy Rev., vol. 75, no. September 2015 , pp. 313-330, 2017.

[3] T. A. Nguyen and M. Aiello, "Energy intelligent buildings based on user activity: A survey," Energy Build., vol. 56, pp. 244-257, 2013.

[4] D. Chwieduk, "Towards sustainable-energy buildings," vol. 76, pp. 211-217, 2003.

[5] G. Parise, L. Martirano, and S. Member, "Daylight impact on energy performance of internal lighting," vol. 49, no. 1, pp. 242-249, 2013.

[6] M. Asif et al., "A review on lighting control technologies in commercial buildings , their performance and affecting factors," Renew. Sustain. Energy Rev., vol. 33, pp. 268-279, 2014.

[7] F. Linhart and J. Scartezzini, "Minimizing lighting power density in office rooms equipped with anidolic daylighting systems," Sol. Energy, vol. 84, no. 4, pp. 587-595, 2010.

[8] M. G. Figueiro, A. Bierman, B. Plitnick, and M. S. Rea, "Preliminary evidence that both blue and red light can induce alertness at night," BMC Neurosci., vol. 10, p. 105, 2009.

[9] L. Sahin and M. G. Figueiro, "Alerting effects of short-wavelength (blue) and long-wavelength (red) lights in the afternoon," Physiol. Behav., vol. 116-117, pp. 1-7, 2013.

[10] T. Roenneberg and R. G. Foster, "Twilight times: Light and the circadian system," Photochem. Photobiol., vol. 66, no. 5, pp. 549-561, 1997.

[11] J. F. D. and C. A. Czeisler, "Effect of light on human cicardian physiology," Sleep Med Clin, vol. 4, no. 2, pp. 165-177, 2009.

[12] M. S. Rea, M. G. Figueiro, J. D. Bullough, and A. Bierman, "A model of phototransduction by the human circadian system," Brain Res. Rev., vol. 50, no. 2, pp. 213-228, 2005.
[13] M. S. Rea, A. Bierman, M. G. Figueiro, and J. D. Bullough, "A new approach to understanding the impact of circadian disruption on human health," J. Circadian Rhythms, vol. 6, pp. 1-14, 2008.

[14] P. R. Boyce, "Review: The impact of light in buildings on human health," in Indoor and Built Environment, 2010, vol. 19, no. 1, pp. 8-20.

[15] M. G. Figueiro et al., "The impact of daytime light exposures on sleep and mood in office workers," Sleep Heal., vol. 3, no. 3, pp. 204-215, 2017.

[16] R. G. Stevens, "Light-at-night, circadian disruption and breast cancer: Assessment of existing evidence," Int. J. Epidemiol., vol. 38, no. 4, pp 963-970, 2009.

[17] E. S. Schernhammer, D. Feskanich, G. Liang, and J. Han, "Rotating night-shift work and lung cancer risk among female nurses in the united states," Am. J. Epidemiol., vol. 178, no. 9, pp. 1434-1441, 2013.

[18] L. Bellia, F. Bisegna, and G. Spada, "Lighting in indoor environments: Visual and non-visual effects of light sources with different spectral power distributions," Build. Environ., vol. 46, no. 10, pp. 1984-1992, 2011.

[19] M. S. Rea and M. G. Figueiro, "Quantifying light-dependent circadian disruption in humans and animal models," Chronobiol. Int., vol. 31, no. 10, pp. 1239-1246, 2014.

[20] I. Chew, D. Karunatilaka, C. P. Tan, and V. Kalavally, "Smart lighting: The way forward? Reviewing the past to shape the future," Energy Build., vol. 149, pp. 180-191, 2017.

[21] P. K. Soori and M. Vishwas, "Lighting control strategy for energy efficient office lighting system design," Energy Build., vol. 66, pp. 329-337, 2013.

[22] H. Zou, Y. Zhou, H. Jiang, S. C. Chien, L. Xie, and C. J. Spanos, "WinLight: A WiFi-based occupancy-driven lighting control system for smart building," Energy Build., vol. 158, pp. 924-938, 2018.

[23] A. Pandharipande and D. Caicedo, "Smart indoor lighting systems with luminaire-based sensing: A review of lighting control approaches," Energy Build., vol. 104, pp. 369-377, 2015.

[24] S. Afshari, S. Mishra, A. Julius, F. Lizarralde, J. D. Wason, and J. T. Wen, "Modeling and control of color tunable lighting systems," Energy Build., vol. 68, no. PARTA, pp. 242-253, 2014.

[25] L. Jia, S. Afshari, S. Mishra, and R. J. Radke, "Simulation for pre-visualizing and tuning lighting controller behavior," Energy Build., vol. 70, pp. 287-302, 2014.

[26] S. A. and S. Mishra, "Decentralized feedback control of smart Lighting systems," December 2014, 2013.

[27] S. Afshari and S. Mishra, "A plug-and-play realization of decentralized feedback control for smart lighting systems," IEEE Trans. Control Syst. Technol., vol. 24, no. 4, pp. 1317-1327, 2016.

[28] C. F. Reinhart, "Lightswitch-2002: A model for manual and automated control of electric lighting and blinds," Sol. Energy, vol. 77, no. 1, pp 15-28, 2004.

[29] S. Tang, V. Kalavally, K. Y. Ng, and J. Parkkinen, "Development of a prototype smart home intelligent lighting control architecture using sensors onboard a mobile computing system," Energy Build., vol. 138, pp. 368-376, 2017.

[30] L. Xu, Y. Pan, Y. Yao, D. Cai, Z. Huang, and N. Linder, "Lighting energy efficiency in offices under different control strategies," Energy Build., vol. 138, pp. 127-139, 2017.

[31] H. B. Gunay, W. O’Brien, I. Beausoleil-Morrison, and B. Huchuk, "On adaptive occupant-learning window blind and lighting controls," Build. Res. Inf., vol. 42, no. 6, pp. 739-756, 2014.

[32] H. B. Gunay, W. O’Brien, I. Beausoleil-Morrison, and S. Gilani, "Development and implementation of an adaptive lighting and blinds control algorithm," Build. Environ., vol. 113, pp. 185-199, 2017.

[33] C. de Bakker, M. Aries, H. Kort, and A. Rosemann, "Occupancy-based lighting control in open-plan office spaces: A state-of-the-art review," Build. Environ., vol. 112, pp. 308-321, 2017.

[34] X. Guo, D. K. Tiller, G. P. Henze, and C. E. Waters, "The performance of occupancy-based lighting control systems: A review," Light. Res. Technol., vol. 42, no. 4, pp. 415-431, 2010.

[35] C. Yin, S. Dadras, X. Huang, J. Mei, H. Malek, and Y. Cheng, "Energy-saving control strategy for lighting system based on multivariate extremum seeking with Newton algorithm," Energy Convers. Manag., vol. 142, pp. 504-522, 2017.

[36] İ. Kiyak, B. Oral, and V. Topuz, "Smart indoor LED lighting design powered by hybrid renewable energy systems," Energy Build., vol. 148, pp. 342-347, 2017.

[37] J. Mardaljevic, L. Heschong, and E. Lee, "Daylight metrics and energy savings," Light. Res. Technol., vol. 41, no. 3, pp. 261-283, 2009. 
[38] AENOR, "Norma UNE-EN 12464-1:2012. Iluminación. Iluminación de los lugares de trabajo. Parte 1: Lugares de trabajo en interiores." 2012.

[39] A. Williams, B. Atkinson, K. Garbesi, E. Page, and F. Rubinstein, "Lighting controls in commercial buildings," LEUKOS - J. Illum. Eng. Soc. North Am., vol. 8, no. 3, pp. 161-180, 2012.

[40] P. Correia da Silva, V. Leal, and M. Andersen, "Occupants interaction with electric lighting and shading systems in real single-occupied offices: Results from a monitoring campaign," Build. Environ., vol. 64, pp. 152-168, 2013.

[41] D. H. W. Li, K. L. Cheung, S. L. Wong, and T. N. T. Lam, "An analysis of energy-efficient light fittings and lighting controls," Appl. Energy, 2010.

[42] M. Vishwas and P. Kumar Soori, "Simple tool for energy analysis of day lighting and artificial lighting for a typical office building lighting system design," Int. J. Energy Eng., vol. 2, no. 6, pp. 332-338, 2012.

[43] A. Pandharipande, D. Caicedo, and X. Wang, "Sensor-driven wireless lighting control: System solutions and services for intelligent buildings," IEEE Sens. J., vol. 14, no. 12, pp. 4207-4215, 2014.

[44] C. F. Reinhart and K. Voss, "Monitoring manual control of electric lighting and blinds," Lighting Research and Technology. 2003.

[45] H. Chen, S. Tan, S. Member, and S. Y. R. Hui, "Nonlinear dimming and correlated color temperature control of bicolor white LED systems," no. September 2015, 2014.

[46] A. T. L. Lee, H. Chen, S. Tan, S. Member, and S. Y. R. Hui, "Precise Dimming and Color Control of LED Systems Based on Color Mixing," no. September, 2015.

[47] S. Buso and G. Spiazzi, "WHITE LIGHT SOLID STATE LAMP WITH LUMINANCE AND COLOR TEMPERATURE CONTROL," pp. 837-843, 2011.

[48] Y. Gao, H. Wu, J. Dong, and G. Q. Zhang, "Constrained optimization of multi-color LED light sources for color temperature control," pp. $102-105$.

[49] I. Fryc, S. W. Brown, Y. Ohno, I. Fryc, S. W. Brown, and Y. Ohno, "Spectral matching with an LED- based spectrally tunable light source," no. September 2005, 2018.

[50] I. Fryc, S. W. Brown, and G. P. Eppeldauer, "LED-based spectrally tunable source for radiometric , photometric , and colorimetric," vol. 44, no. November 2005, pp. 1-8, 2018.

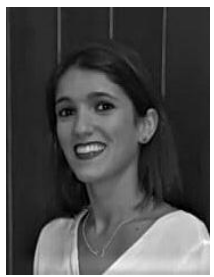

R. M. López studied Architecture at the University of Seville.

She is a scholarship researcher at the Department of Building Construction I, University of Seville, Spain.

She develops research on the field of control systems and its relationship with the architectural design and human health.

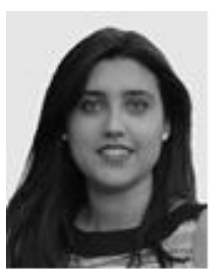

M. T. Aguilar studied architecture at the University of Seville.

She is a scholarship researcher at the Department of Building Construction I, University of Seville, Spain. She develops research on the field of lighting and its relationship with the architectural design and human health.

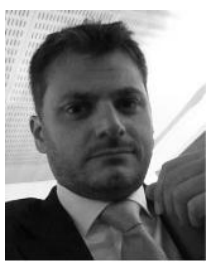

S. Domínguez-Amarillo is a vice dean in the College of Architecture and Professor in Department of Building Construction I at the University of Seville, Spain. He is a member of the research group TEP-130. In his professional career he acts as Expert Consultant on Hi-performance systems for buildings and in the assessment of sustainability and energy efficiency of buildings and their urban environment. He has extensive background as adviser on environmental control for Cultural Heritage, with a wide portfolio of national and international projects.

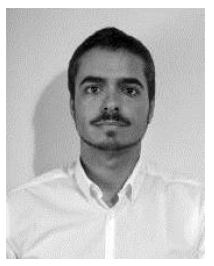

M. A. Campano is a professor at the Department of Building Construction I, University of Seville, Spain. He is a member of the research group TEP-130, which is focused on sustainability, energy efficiency, lighting, acoustics and optics related to building design and heritage refurbishment

He develops research on the field of energy efficiency, indoor environmental comfort and daylighting, as well as their relationship with the architectural design 